\section{Lung transplantation for pulmonary sarcoidosis. Twenty-five years of experience in the USA}

\section{ABSTRACT}

Objective Lung transplantation is the ultimate treatment for end-stage pulmonary sarcoidosis. Post-transplant survival outcomes remain unclear.

Methods Survival models were used to assess survival and graft outcomes in patients with sarcoid among 20896 lung transplants performed in the USA.

Results 695 lung recipients were transplanted for pulmonary sarcoidosis. Sarcoid lung recipients had similar median survival rate $(69.7$ months (IQR 60.2-79.3)) compared with the nonsarcoid lung recipients (63.1 months (IQR 61.4-64.8), $\mathrm{p}=0.88$ ). In multivariate Cox regression, sarcoidosis was not independently associated with worse mortality (HR 0.96 (95\% CI 0.85 to 1.08 ), $\mathrm{p}=0.51$ ). Among the sarcoid lung recipients, double lung transplantation (HR 0.76 (0.58 to $0.99), \mathrm{p}=0.04)$ and lung allocation score era (HR 0.74 (0.56 to 0.97$), p=0.03$ ) were associated with improved survival.

Conclusions Recipients of lung transplants for pulmonary sarcoidosis had similar outcomes compared with nonsarcoid lung recipients.

\section{INTRODUCTION}

Sarcoidosis is a systemic multiorgan disorder characterised by CD4 T-lymphocytes response and non-caseating granulomata. Approximately 95\% of patients with sarcoidosis develop pulmonary disease during their lifetime. A small minority progress to develop end-stage fibrocystic disease. ${ }^{1}$ Lung transplantation is often performed in irreversible advanced cases who have failed medical therapy. $^{2}$ However, post-transplant survival and graft outcomes remain unclear, primarily due to the recurring nature of the disease, ${ }^{3}$ extrapulmonary involvement and chronic lung infections. ${ }^{4}$ Given the paucity of data reporting outcomes of transplantation for sarcoidosis, ${ }^{5-7}$ the objective of this study was to examine the outcomes associated with lung transplantation for pulmonary sarcoidosis in a large multicentre registry-based cohort.

\section{PATIENTS AND METHODS}

The Organ Procurement and Transplantation Network database was queried for all lung-only first-time transplants between 1987 and 2012 . Patients diagnosed with sarcoidosis were compared with all other transplanted cases. The primary outcome was median survival rate. The secondary outcomes were allograft dysfunction rates.

\section{STATISTICAL ANALYSIS}

The method of Kaplan-Meier with log-rank tests were used to compare unadjusted survival rates between sarcoidosis and control groups. Multivariate Cox regression models were performed to assess the independent contribution of clinical variables on all-cause mortality in the total cohort and in the sarcoid cohorts (see online supplementary table S1).

\section{RESULTS}

Since 1987, 20896 patients received a lung transplant, with a median follow-up of 33.5 months (range 0-268). Of those, 695 lung recipients (3.3\%) were transplanted for pulmonary sarcoidosis. Compared with the non-sarcoid lung recipients, sarcoid lung recipients were of similar age $(p=0.55)$; however, they included more female $(p<0.001)$, fewer Caucasian $(p<0.001)$ and more double lung transplant recipients $(p<0.001)$. The sarcoid lung recipients had similar median survival rate (69.7 months (IQR 60.279.3)) compared with the non-sarcoid lung recipients (63.1 months (IQR 61.464.8 ), log-rank $\mathrm{p}=0.88$ ) (figure 1 ). The two groups had similar rates of bronchioalveolitis obliterans syndrome (BOS) $(\mathrm{p}=0.42)$, and new $\mathrm{O}_{2}$ requirements $(p=0.9)$. Fewer sarcoid lung recipients underwent retransplantation $(\mathrm{p}=0.03)$ (table 1). Multivariate Cox regression analysis demonstrated that sarcoidosis was not independently associated with worse allcause mortality (HR 0.96 (95\% CI 0.85 to 1.08), $\mathrm{p}=0.51$ ) (see online supplementary table S1). Among sarcoid lung recipients, only double lung transplantation $(0.76$ (0.58 to 0.99$), \mathrm{p}=0.04)$ and lung allocation score (LAS) era (0.74 (0.56 to 0.97$)$, $\mathrm{p}=0.03$ ) emerged as protective factors (see online supplementary tables $\mathrm{S} 1-\mathrm{S} 3$ ).

\section{DISCUSSION}

Transplantation for sarcoidosis remains uncommon, with rates ranging from 3\% to $5 \%$. Prior smaller-scale studies have reported similar survival rates to our findings, with 5-year survival rate of approximately $50 \%$, similar to non-sarcoid lung transplants. ${ }^{5} 8$ Additionally, sarcoid diagnosis was not associated with worse hazard of survival (HR 0.94 (0.33 to 2.67)) in one study. ${ }^{8}$ Conversely, data remain limited on graft outcomes. In our study, similar rates of $\mathrm{BOS}$, new $\mathrm{O}_{2}$ requirements and lower rates of retransplantation supported equivalent outcomes to non-sarcoid lung recipients, in spite of the known risks of disease recurrence and its systemic nature.

The LAS system was implemented in the USA in 2005 , and prioritised candidacy by expected post-transplant survival and predicted waiting list urgency in attempt to decrease the waitlist mortality rate and waiting time. ${ }^{9}$ Our data showed that LAS was associated with improved survival

Figure 1 Unadjusted Kaplan-Meier survival curve comparing sarcoid versus non-sarcoid transplant recipients. 
Table 1 Baseline characteristics and transplantation outcomes

\begin{tabular}{|c|c|c|c|c|}
\hline Variable & $\begin{array}{l}\text { Total } \\
(n=20 \text { 971) }\end{array}$ & $\begin{array}{l}\text { Sarcoid } \\
(n=695,3.3 \%)\end{array}$ & $\begin{array}{l}\text { Non-sarcoid } \\
(n=20201,96.7 \%)\end{array}$ & p Value \\
\hline \multicolumn{5}{|l|}{ Pretransplant } \\
\hline Age, year, mean $\pm S D$ & $50.2 \pm 15.0$ & $49.9 \pm 8.7$ & $50.2 \pm 15.1$ & 0.55 \\
\hline Males, n (\%) & $11165(53.2)$ & $300(43.0)$ & 10865 (53.6) & $<0.001$ \\
\hline Caucasian, n (\%) & 18309 (87.3) & $227(32.6)$ & $18082(89.2)$ & $<0.001$ \\
\hline Waiting time, month, median (range) & $5.3(0-195)$ & $5.9(0-97)$ & $5.3(0-195)$ & 0.24 \\
\hline \multicolumn{5}{|l|}{ Life support, n (\%) } \\
\hline Inhaled NO & $18(0.1)$ & $0(0)$ & $18(0.1)$ & 0.43 \\
\hline Prostacyclin & $63(0.3)$ & $4(0.5)$ & $59(0.3)$ & 0.41 \\
\hline ECMO-bridge & $43(0.2)$ & $0(0)$ & $43(0.2)$ & 0.22 \\
\hline Mechanical ventilation & $312(1.5)$ & $5(0.7)$ & $307(1.5)$ & 0.10 \\
\hline \multicolumn{5}{|l|}{ Transplant } \\
\hline Graft ischemic time, hour, mean \pm SD & $4.8 \pm 1.7$ & $5.1 \pm 1.8$ & $4.8 \pm 1.7$ & $<0.001$ \\
\hline Double lung transplant, n (\%) & $12011(57.3)$ & $480(68.9)$ & $11531(56.9)$ & $<0.001$ \\
\hline \multicolumn{5}{|l|}{ Donor } \\
\hline Age, year, mean $\pm S D$ & $31.9 \pm 14.2$ & $33.7 \pm 13.7$ & $31.8 \pm 14.1$ & $<0.001$ \\
\hline Male, n (\%) & $12861(61.3)$ & $369(52.9)$ & 12492 (61.6) & $<0.001$ \\
\hline Caucasian, n (\%) & $14285(68.1)$ & $432(62)$ & $13853(68.3)$ & $<0.001$ \\
\hline LAS era, post, n (\%) & $10245(49.0)$ & $381(54.8)$ & $9864(48.8)$ & 0.002 \\
\hline \multicolumn{5}{|l|}{ Post-transplant } \\
\hline \multicolumn{5}{|l|}{ Survival } \\
\hline Median (IQR), months & $63.4(61.7-65.0)$ & $69.7(60.2-79.3)$ & $63.1(61.4-64.8)$ & 0.88 \\
\hline 1 year $(\%)$ & 72 & 71 & 73 & \\
\hline 5 years $(\%)$ & 47 & 50 & 46 & \\
\hline 10 years $(\%)$ & 26 & 28 & 26 & \\
\hline \multicolumn{5}{|l|}{ Allograft dysfunction } \\
\hline Retransplanted, n (\%) & $787(3.8)$ & $15(2.2)$ & $772(3.8)$ & 0.03 \\
\hline BOS, n (\%) & 7283 (35.6) & $222(31.9)$ & $7061(35.7)$ & 0.42 \\
\hline New $\mathrm{O}_{2}$ requirement, $\mathrm{n}(\%)$ & $1065(27.8)$ & $129(27.5)$ & $3936(27.8)$ & 0.9 \\
\hline
\end{tabular}

benefit in sarcoid lung transplants up until 7 years of follow-up, after which that survival benefit started to decline. This finding suggests a potential negative longterm effect, and an unintentional consequence of emphasis on the 1-year survival. Nonetheless, implementation of the LAS system has decreased the list waiting times, which may have resulted in the improved graft outcomes identified in our study.

Lung transplantation is unique in that donor organ can be used for one recipient for a double transplant; or split to potentially benefit two patients, each with a single lung transplant. Similar to our sarcoidosis cohort, long-term outcomes also favoured double lung transplantation in patients with idiopathic pulmonary fibrosis. ${ }^{10}$ Disease recurrence ${ }^{3} 5$ and progression of disease despite ongoing immune suppression could potentially explain the need for double transplantation.
In conclusion, the diagnosis of sarcoidosis did not appear to be associated with worse lung transplantation survival or allograft dysfunction.

\section{Ziad Taimeh, ${ }^{1}$ Marshall I Hertz, ${ }^{2}$ Sara Shumway, ${ }^{3}$ Marc Pritzker ${ }^{1}$}

${ }^{1}$ Lillehei Heart Institute, University of Minnesota School of Medicine, Minneapolis, Minnesota, USA Sleep Medicine, University of Minnesota School of Medicine, Minneapolis, Minnesota, USA ${ }^{3}$ Department of Cardiothoracic Surgery, University of Minnesota School of Medicine, Minneapolis, Minnesota, USA

Correspondence to Dr Ziad Taimeh, Lillehei Heart Institute, University of Minnesota School of Medicine, 420 Delaware street SE, MMC 508, Minneapolis, MN 55455, USA; taime001@umn.edu

Contributors All authors had a significant role in the study. ZT formulated the hypothesis, performed the statistical analysis and wrote the manuscript. MIH formulated the hypothesis and wrote the manuscript.
${ }^{2}$ Department of Pulmonary, Allergy, Critical Care and
SS wrote the manuscript. MP formulated the hypothesis and wrote the manuscript.

Funding This work was supported in part by Health Resources and Services Administration contract 234-2005-370011 C.

Competing interests None declared.

Provenance and peer review Not commissioned; externally peer reviewed.

- Additional material is published online only. To view please visit the journal online (http://dx.doi.org/10. 1136/thoraxjnl-2015-207497)

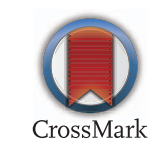

To cite Taimeh Z, Hertz MI, Shumway $S$, et al. Thorax 2016;71:378-379.

Received 25 June 2015

Revised 19 December 2015

Accepted 23 December 2015

Published Online First 18 January 2016

Thorax 2016:71:378-379.

doi:10.1136/thoraxjnl-2015-207497

\section{REFERENCES}

1 Baughman RP, Teirstein AS, Judson MA, et al. Clinical characteristics of patients in a case control study of sarcoidosis. Am J Respir Crit Care Med 2001;164(10 Pt 1):1885-9.

2 Orens JB, Estenne M, Arcasoy $S$, et al. International guidelines for the selection of lung transplant candidates: 2006 update - a consensus report from the Pulmonary Scientific Council of the International Society for Heart and Lung Transplantation. J Heart Lung Transplant 2006;25:745-55.

3 Martinez FJ, Orens JB, Deeb M, et al. Recurrence of sarcoidosis following bilateral allogeneic lung transplantation. Chest 1994;106:1597-9.

4 Amin EN, Closser DR, Crouser ED. Current best practice in the management of pulmonary and systemic sarcoidosis. Ther Adv Respir Dis 2014;8:111-32.

5 Walker S, Mikhail G, Banner N, et al. Medium term results of lung transplantation for end stage pulmonary sarcoidosis. Thorax 1998;53:281-4.

6 Nunley DR, Hattler B, Keenan RJ, et al. Lung transplantation for end-stage pulmonary sarcoidosis. Sarcoidosis Vasc Diffuse Lung Dis 1999;16:93-100.

7 Arcasoy SM, Christie JD, Pochettino A, et al. Characteristics and outcomes of patients with sarcoidosis listed for lung transplantation. Chest 2001;120:873-80.

8 Wille KM, Gaggar A, Hajari AS, et al. Bronchiolitis obliterans syndrome and survival following lung transplantation for patients with sarcoidosis. Sarcoidosis Vasc Diffuse Lung Dis 2008;25:117-24.

9 Egan TM, Murray S, Bustami RT, et al. Development of the new lung allocation system in the United States. Am J Transplant 2006;6(5 Pt 2):1212-27.

10 Kistler KD, Nalysnyk L, Rotella P, et al. Lung transplantation in idiopathic pulmonary fibrosis: a systematic review of the literature. BMC Pulm Med 2014;14:139. 